\title{
Sacral stress fracture in an amateur rugby player: a case report
}

\author{
Yasuhiro Takahashi ${ }^{1 *}$, Takashi Kobayashi ${ }^{1}$, Naohisa Miyakoshi ${ }^{2}$ Eiji Abe ${ }^{1}$, Toshiki Abe ${ }^{1}$, Kazuma Kikuchi ${ }^{1}$ \\ and Yoichi Shimada ${ }^{2}$
}

\begin{abstract}
Background: Sacral stress fracture is an uncommon cause of back pain. The majority of previously reported cases have been in runners. The purpose of this case report was to describe a case of sacral stress fracture in an amateur rugby player.

Case presentation: A healthy 18-year-old Japanese boy who was a rugby player presented with a 3-week history of lumbago. Sagittal and axial magnetic resonance imaging failed to reveal any reason for lumbago in his lumbar region. On his second presentation, 4 weeks later, his lumbago was so severe that he could not walk without a cane. A second magnetic resonance imaging revealed bone marrow edema with T1-weighted hypointensity and short inversion time inversion recovery hyperintensity at his left sacrum in coronal sections, consistent with stress fracture. Pain was relieved with rest and 1 year later he was able to return to rugby without lumbago or left buttock pain.
\end{abstract}

Conclusions: Sacral stress fracture can cause low back pain in athletes. Coronal magnetic resonance imaging appears to be an effective option for diagnosis.

Keywords: Sacral stress fracture, Athlete, Pediatric, Rugby

\section{Background}

Athletes may experience low back pain. Stress fractures have been described as a cause of back pain, particularly fracture of the pars interarticularis of the vertebrae $[1,2]$. Sacral stress fracture is an uncommon cause of back pain, and the majority of previously reported cases have involved runners [3]. The purpose of this case report was to describe a case of sacral stress fracture in an amateur rugby player.

\section{Case presentation}

A healthy 18-year-old Japanese boy who was a rugby player presented with a 3-week history of lumbago. He noticed lumbago after he played rugby. He did not have a clear event of pain onset. Pain had increased over time and was limiting his ability to exercise. Tenderness was identified in his left lumbar paravertebral muscles. Strength, sensation, and reflexes were normal in both

\footnotetext{
*Correspondence: yas_0530@yahoo.co.jp

${ }^{1}$ Department of Orthopedic Surgery, Akita Kousei Medical Center, 1-1-1

lijima-Nishifukuro, Akita 011-0948, Japan

Full list of author information is available at the end of the article
}

his lower limbs. Because previous plain films of his lumbar spine had proven uninformative, magnetic resonance imaging (MRI) of his lumbar spine was performed. Sagittal and axial images failed to show any potential causes of the lumbago in his lumbar region. He continued with his exercise regime and pain increased. He was again admitted to our hospital 1 month after his initial admission. At the time of this second presentation, his lumbago was so severe that he could not walk without a cane. His lumbago was exacerbated on lumbar extension and with load bearing by his left limbs. Tenderness was identified in the region of his left sacroiliac joint. Strength, sensation, and reflexes remained normal in both lower limbs. MRI was again performed, including coronal sections on suspicion of spondylolisthesis. Coronal imaging revealed bone marrow edema with hypointensity on T1-weighted imaging and hyperintensity on short inversion time inversion recovery (STIR) at his left sacrum, consistent with stress fractures (Fig. 1). Pain was relieved with rest, and our patient was able to resume running 4 weeks after second presentation, returning to rugby after a 

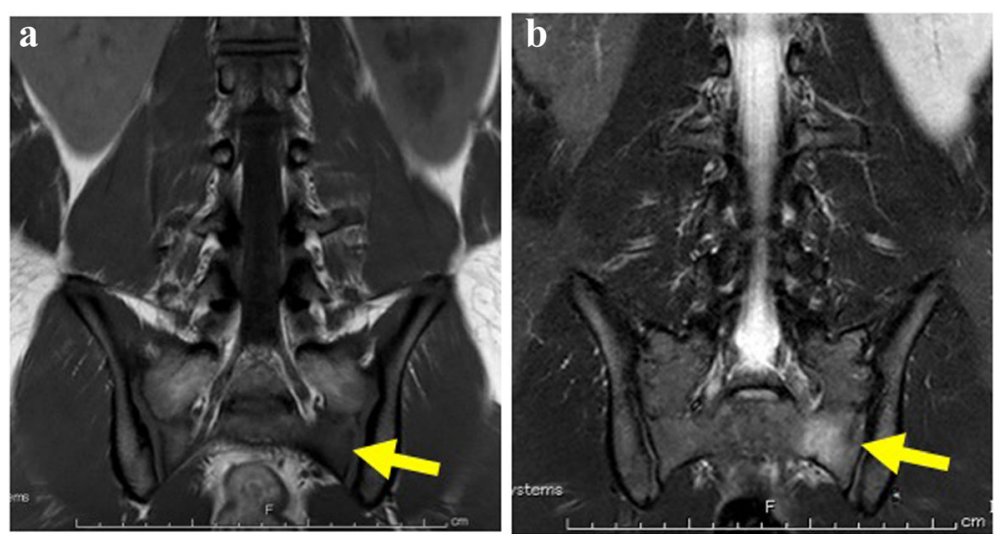

Fig. 1 Coronal T1-weighted (a) and short inversion time inversion recovery $(\mathbf{b})$ images of the pelvis onsecond presentation. Bone marrow edema in the left sacral ala (arrow) indicates left sacral fracture

further 2 months. A follow-up MRI at 3 months after his second presentation showed a hypointense area on T1-weighted imaging and a hyperintense area on STIR at his right sacrum in coronal sections (Fig. 2). A follow-up MRI at 6 months after his second presentation showed no evidence of fractures. He was playing rugby without any lumbago or left buttock pain 1 year after his second presentation.

\section{Discussion}

Acute low back pain is common in athletes. Spondylolysis is the most common cause of back pain in adolescents [2].

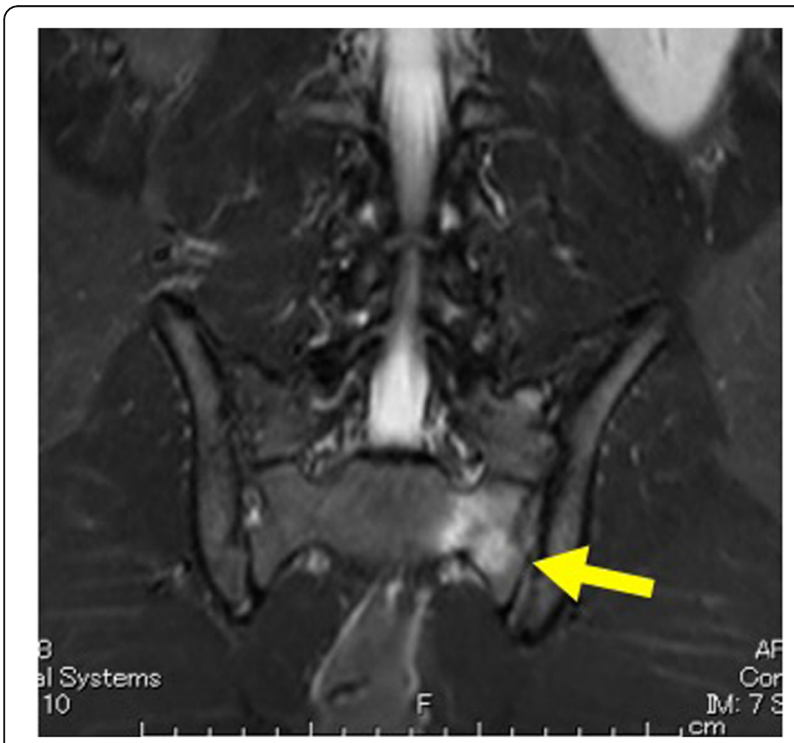

Fig. 2 Coronal short inversion time inversion recovery sequence 3 months after the second presentation. Linear area of signal hypointensity in the left sacral ala (arrow) indicates the fracture line, with surrounding edema
MRI is the most effective modality for detecting pars injuries [4], and images in the coronal plane are known to be useful in the early diagnosis of spondylolysis [5]. We consider coronal MRI when spondylolysis is suspected. Spondylolysis was not initially suspected in this case, and coronal MRI was therefore not considered. We could not identify any abnormalities on sagittal or axial MRI. On the second admission, lumbar extension was limited and spondylolysis was suspected, so coronal MRI was selected and revealed sacral fractures. We diagnosed stress fracture because of our patient's gradual onset of lumbago. Coronal MRI offers advantages in not only diagnosing spondylolysis, but also diagnosing sacral stress fractures in athletes.

Sacral stress fractures are an uncommon cause of low back pain. Although the majority of cases previously reported have been in runners [3], and the mean age in the literature is 26 years [3], our patient was an 18-yearold rugby player. Clinical findings are characterized by lumbago, buttock pain, or groin pain [3]. These fractures are thought to often result from training errors when an excessive or rapid increase in the training regimen causes muscle fatigue, with resultant stress on the bone that exceeds its ability to regenerate [6].

Treatment involves rest and activity modification. Most patients are able to return to their normal levels of activity within 4 to 6 weeks [3]. Our patient showed rapid improvement of symptoms with relative rest, and was able to run after 4 weeks and return to rugby after 12 weeks.

\section{Conclusions}

Sacral stress fractures can be a cause of low back pain in athletes. Coronal MRI is an effective option for diagnosing this pathology. 


\section{Abbreviations}

MRI: Magnetic resonance imaging; STIR: Short inversion time inversion recovery

\section{Acknowledgements}

The authors wish to thank Mamiko Kondo for her valuable assistance with the editing of this manuscript.

\section{Funding}

No funding was received for this study.

\section{Availability of data and materials}

The authors agree to make the raw data and materials described in our manuscript freely available.

\section{Authors' contributions}

$Y T$ and TK were the major contributors in writing the manuscript. NM, EA TA, KK, and YS supervised the whole work. All authors read and approved the final manuscript.

\section{Competing interests}

The authors declare that they have no competing interests.

\section{Consent for publication}

Written informed consent was obtained from the patient for publication of this case report and accompanying images. A copy of the written consent is available for review by the Editor-in-Chief of this journal.

\section{Author details}

'Department of Orthopedic Surgery, Akita Kousei Medical Center, 1-1-1

lijima-Nishifukuro, Akita 011-0948, Japan. 'Department of Orthopedic Surgery, Akita University Graduate School of Medicine, 1-1-1 Hondo, Akita 010-8543,

Japan.

Received: 21 December 2015 Accepted: 24 October 2016

Published online: 16 November 2016

\section{References}

1. Micheli $L$, , Wood R. Back pain in young athletes. Significant differences from adults in causes and patterns. Arch Pediatr Adolesc Med. 1995;149:15-8.

2. Sucato DJ, Micheli LJ, Estes AR, Tolo VT. Spine problems in young athletes. Instr Course Lect. 2012:61:499-511.

3. Shah MK, Stewart GW. Sacral stress fractures: an unusual cause of low back pain in an athlete. Spine. 2002;27:E104-8.

4. Rush JK, Astur N, Scott S, Kelly DM, Sawyer JR, Warner Jr WC. Use of magnetic resonance imaging in the evaluation of spondylolysis. J Pediatr Orthop. 2015;35:271-5

5. Yamane T, Yoshida T, Mimatsu K. Early diagnosis of lumbar spondylolysis by MRI. J Bone Joint Surg (Br). 1993;75:764-8.

6. Miller C, Major N, Toth A. Pelvic stress injuries in the athlete: management and prevention. Sports Med. 2003;33:1003-12

\section{Submit your next manuscript to BioMed Central} and we will help you at every step:

- We accept pre-submission inquiries

- Our selector tool helps you to find the most relevant journal

- We provide round the clock customer support

- Convenient online submission

- Thorough peer review

- Inclusion in PubMed and all major indexing services

- Maximum visibility for your research

Submit your manuscript at www.biomedcentral.com/submit 